\title{
Modeling of PWM Inverters for Harmonic Reduction under Various Load Conditions using Fuzzy Controller
}

\author{
Romia Bhatnagar \\ ABES Engineering College \\ $19^{\text {th }} \mathrm{Km}$ Stone, Delhi-Hapur \\ Road, \\ $\mathrm{NH}-24$, Vijay Nagar, \\ Ghaziabad, U.P
}

\author{
Malik M. Anwer \\ ABES Engineering College \\ $19^{\text {th }} \mathrm{Km}$ Stone, Delhi-Hapur \\ Road, \\ $\mathrm{NH}-24$, Vijay Nagar, \\ Ghaziabad, U.P
}

\author{
A.K. Arora \\ ABES Engineering College \\ $19^{\text {th }} \mathrm{Km}$ Stone, Delhi-Hapur \\ Road, \\ $\mathrm{NH}-24$, Vijay Nagar, \\ Ghaziabad, U.P
}

\begin{abstract}
This paper presents the method for the usage of PWM inverters for various different and accurate applications. As it is the great requirement for processes to provide the best and accurate results in different working conditions. So for their uninterrupted working in that field, there is need to employ the device which works during the failure of power supply system. By keeping this requirement at high priority, the method for generating pure sinusoidal voltage waveform at the PWM inverter output is described in this paper. Harmonics are the basic and old problem which continue to affect the performance of the power systems in various applications depending upon the types of loads (linear \& non-linear) [1].Thus, there is need to limit such kind of distortion. So, in this paper Fuzzy logic control mechanism is presented for the modifications in PWM inverter of the controllers' structure. Results of the MATLAB/Simulink simulation show that inverter output current is in sinusoidal waveform and in phase with line voltage, and current harmonics are in the limits of international standards $(<5 \%)[2]$. The results gained in this work prove the validity of the proposed controller of having an output voltage with minimum distortion.
\end{abstract}

THD: Its full form is Total Harmonic Distortion and defined as the root mean square value of the harmonic components to the fundamental component.

Keywords: - Fuzzy Logic Controller, Membership functions, PWM (pulse width modulation) inverters, controllers' circuit design, TDH, model.

\section{INTRODUCTION}

Voltage source inverters (VSIs) are widely used in power supplies, power quality controllers, renewable energy, industrial applications etc. They are at the heart of applications requiring an AC supply from a DC source. Therefore, it is important that they are designed to be robust and efficient, especially in industrial energy applications where inverter failure can cause inconvenience in the production purposes. Producing sinusoidal signal provided constant power supply for its generation, a full-bridge PWM inverter along with filter is employed. In this paper, Matlab/ Simulink is used to model single-phase full-bridge VSI. This software package is designed for modeling, simulating and analyzing dynamic systems. For the applications, the desired output of the inverter must be pure sinusoidal but it can't be obtained, which means harmonic contents are there in high proportionate [3]. For controlling and eliminating the harmonic values, many technologies have been applied using various techniques and controllers. The basic idea behind many of the technologies is to control the gate current of the switching devices in the bridge circuit. This method is used to variate the pulse widths of these gate pulses to generate modulated control waveform and this has become the base for new technologies. According to the based technologies conventional closed loop control schemes had been employed for automation purpose.

Recently, fuzzy logic controllers are gaining momentum in many applications. In this paper, a controller based on fuzzy set theory [4] [10] is proposed. Superiority of FLC's over the conventional controllers can be considered as it can work with imprecise inputs, can handle nonlinearity and it is more robust than conventional nonlinear controllers [5] [6]. Also, each rule addresses a wider scenario of operating conditions and ensures the same performance even with change in temperature, variation in system parameter with aging or with change in operating conditions. Here the compatibility of the system is shown with various load conditions to demonstrate the increased working range of the system. That's why comparison is made under different load conditions by discussing about the important parameter called Total Harmonic Distortion (TDH).

This paper explains how FLC has been proved a boon for industrial applications. It is quiet easy to be handled there due to quick maintenance processes availability and explores the potential and feasibility of fuzzy logic control schemes that are suitable for harmonic current mitigation and inverter voltage control to improve the performances. The performance of fuzzy controller is evaluated through computer simulations under steady state and transient conditions. The results show that, the proposed mechanism with fuzzy logic controller is capable of providing sinusoidal source voltage(s) with low harmonic distortion.

\section{HARMONIC DISTORTION IN POWER SYSTEMS}

Pulse Width Modulated (PWM) inverters are the most commonly used. These inverters are capable of producing ac voltages of variable magnitude as well as variable frequency. It is expected that the output voltage would result in a good quality sinusoidal voltage waveform of desired fundamental frequency and magnitude after some filtering. One of the major issues with PWM is the presence of harmonics. The higher order harmonics around the carrier frequency are relatively easier to filter out, but the lower order harmonics, though larger in magnitude in comparison to higher order harmonics, often cause problems in certain applications. In most power systems certain loading conditions can cause harmonic distortion to the associated voltage waveform, which may adversely affect certain types of connected load [7]. When an electrical load is 
connected to an AC electricity source, it will draw current. And depending upon the load, different wave shapes are generated. That is, the input current waveform carries a number of harmonics.

This is shown in the given figure below:

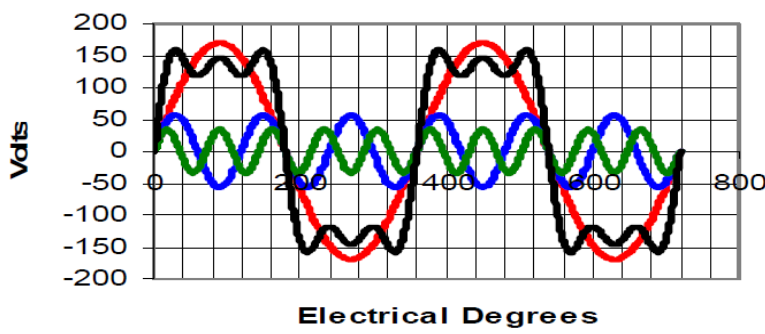

- Sine Wave

$1 / 3$ of Third Harmonic

$1 / 5$ of Fifth Harmonic

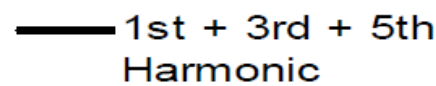

Figure 1: Waveforms of harmonic orders along with fundamental component

These harmonic distortions, by Fourier analysis, are components that have frequencies that are integer multiples of the fundamental frequency [8].Its complete form is the THD which can be calculated from the square root of the sum of the squares of the RMS magnitudes of the individual harmonics, relative to the RMS magnitude of the fundamental component.

\section{HARMONIC ANALYSIS OF PWM INVERTER OUTPUT}

All PWM techniques generate output voltages resulting in a sinusoidal voltage waveform of desired fundamental frequency and magnitude. Though filtering is used to achieve a reduction in the harmonic content of the signal, it is not always possible to remove the lower order harmonics. By proper switching control, the magnitudes of lower order harmonic voltages can be reduced, often at the cost of increasing the magnitudes of higher order harmonic voltages, which theoretically is easier to filter out. Among all PWM techniques, sinusoidal pulse width modulation (SPWM) is the most popular as it has many advantages [2], best being the linearity in controlling the fundamental component.

\section{CHARACTERSTICS OF LOADS}

In the past, there was less distortion in the power systems as there were no complex types of loads. There have been continuous increments in the characteristic of the loads being used. Now, in the present scenario many complex devices have been employed in industrial, commercial, residential area etc. There are various categories of loads which are used in common. Namely, for some types of load, the current drawn is also a sine wave. These loads are called linear loads, and the current drawn may be in phase with the supply voltage (resistive loads), or may lead the voltage (capacitive loads) or may lag the voltage (inductive loads). For other types of load, however, the current drawn by the load may not be sinusoidal.
This type load is known as non-linear loads [9]. Here in this paper the effects of various resistive and inductive types of loads are deployed to demonstrate the appropriate functioning of the designed system.

\section{INTRODUCTION OF FUZZY LOGIC}

Fuzzy logic concept has been into existence since 1965 when it was introduced by Lofti A. Zadeh. Fuzzy logic, however, has not been widely used since 1965; [11]. The idea of fuzzy sets is that the members are not restricted to true or false definitions. A member in a fuzzy set has a degree of membership to the set. For example, the set of voltage values can be classified using a bivalent set as either high or not high. This would require some cut-off value where any voltage greater than that cut-off value is 'high' and any voltage less than that value are 'not high'. If the cut-off point is at $50 \mathrm{~V}$ then this set does not differentiate between a voltage that is $20 \mathrm{~V}$ and a voltage of $49 \mathrm{~V}$. They are both 'not high'.

If a fuzzy set were to be used in this situation each member of the set, or each voltage value, would have a degree of membership to the set of highness. The function that determines this degree of membership is called the fuzzy membership function (Figure 2)

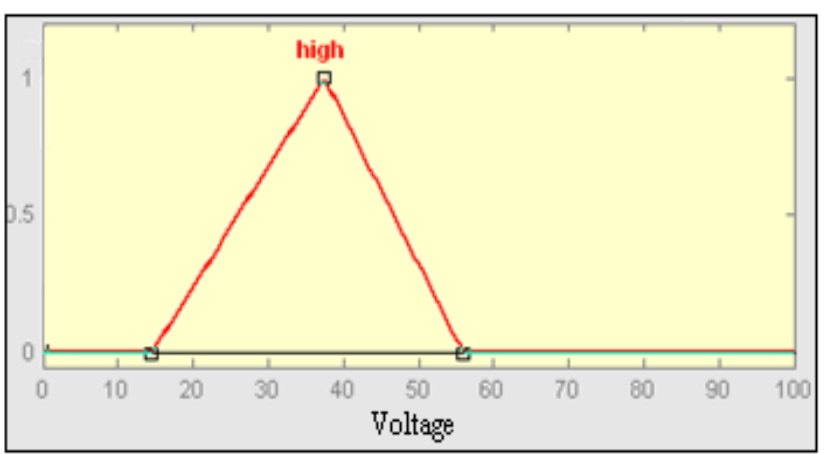

Figure 2: Fuzzy membership function for high value of voltage

There is countless different membership function topologies that can be used; the most common are triangular, Gaussian and sigmoidal. The above function is a triangular function. The attributes of the membership function can be modified based on the desired input [12]. If the relevant voltage range was between 20 and 60 volts, for example, and more weight was needed for higher voltage values then an appropriate membership function can be determined.

\section{FUZZY LOGIC CONTROLLER}

Fuzzy controller is a non-linear controller that does not require a precise mathematical model for its design [4]. It is obviously of great importance when the mathematical model is difficult to obtain due to the complexity and uncertainties of the system. In essence, fuzzy controller is a linguistic-based controller that tries to emulate the way a human thinks in solving a particular problem. The basic fuzzy logic control system is composed of a set of input membership functions, a rule-based controller, and a defuzzification process.

The fuzzy logic input uses member functions to determine the fuzzy value of the input. There can be any number of inputs to a fuzzy system and each one of these inputs can have several membership functions. The set of membership functions for each input can be manipulated to add weight to different 
inputs. The output also has a set of membership functions. These membership functions define the possible responses and outputs of the system [9]. The fuzzy inference engine is the heart of the fuzzy logic control system. It is a rule based controller that uses If-Then statements to relate the input to the desired output [13].

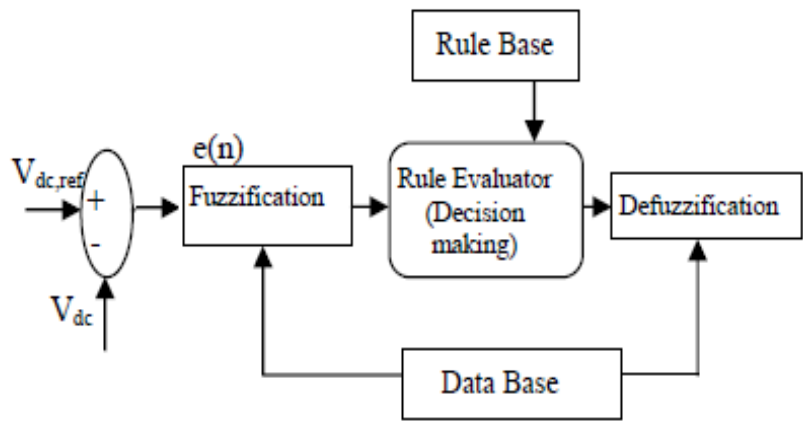

Figure 3: Structure of fuzzy logic system

The fuzzy inputs are combined based on these rules and the degree of membership in each function set. The output membership functions are then manipulated based on the controller for each rule. All of the output member functions are then combined into one aggregate topology. The defuzzification process then chooses the desired finite output from this aggregate fuzzy set. There are several ways to do this such as weighted averages, centroids, or bisectors. This produces the desired result for the output.

FLC is the combination of various different processes which are shown above in the figure 3.It means a fuzzy logic controller comprises of numbers of methods [14] which are described below in stepwise form. Here the processes are explained in general format as explained above are described in detail below:

\subsection{Fuzzification}

Fuzzy logic uses linguistic variables instead of numerical variables. In a control system, error between reference signal and output signal can be assigned as (for example) Negative Big (NB), Negative Medium (NM), Negative Small (NS), Zero (ZE), Positive small (PS), Positive Medium (PM), Positive Big (PB). The triangular membership function is used for fuzzifications. The process of fuzzification convert numerical variable (real number) to a linguistic variable (fuzzy number).

\subsection{Rule Elevator}

Conventional controllers like PI and PID have control gains which are numerical values. Fuzzy logic controller uses linguistic variables instead of the numerical values. The linguistic variables of error signal taken as input $\left(\mathrm{e}_{\mathrm{n}}\right)$ and output is represented as in the form of degree of membership functions. The basic fuzzy set operations needed for evaluation of rules are $\operatorname{AND}(\cap), \mathrm{OR}(U)$ and $\operatorname{NOT}(-)$.

\subsection{Defuzzification}

The rules of fuzzy logic generate demanded output in a linguistic variable, according to real world requirements, linguistic variables have to be transformed to crisp output (Real number). The choices available for defuzzification are numerous. So far the choice of strategy is a compromise between accuracy and computational intensity.

\subsection{Database}

The Database stores the definition of the membership function involved by fuzzifier and defuzzifier. Storage arrangement is a compromise between available memory and microprocessor stages of the digital controller chip.

\section{THE HARMONIC DISTORTION FUZZY MODEL}

The PWM fuzzy model for the harmonic distortion diagnostic is implemented in MATLAB/Simulink using the fuzzy logic toolbox. This toolbox allows for the creation of input membership functions, fuzzy control rules, and output membership functions [15]. In this system which is implemented in Simulink the system will need to have two inputs: the harmonic contained voltage error and the rate of change of error voltage. These two inputs will then be combined by multiplexer and processed by a fuzzy logic controller that will output a degree of correction. This degree of correctness is decoded into one of the output: small, average, large. A simple diagnostic system was created as shown in Figure 4

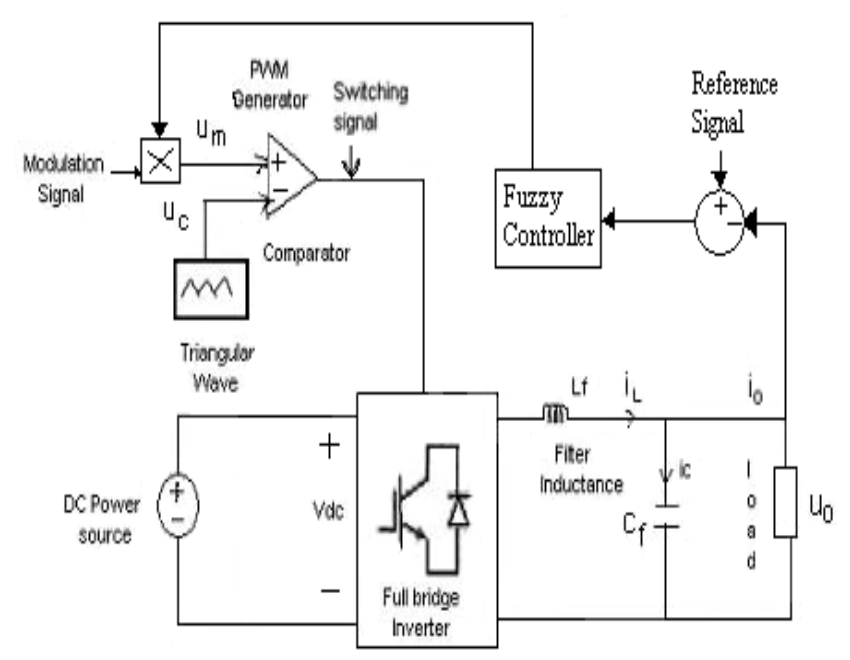

Figure 4: Sine-wave approximation using fuzzy logic controller

The modulating signal is a sinusoidal signal having amplitude in the range of -1 to +1 given in figure 5 . One of the inputs to the FLC is $\mathrm{V}_{\text {ref }}-\mathrm{V}_{\mathrm{o}}$.

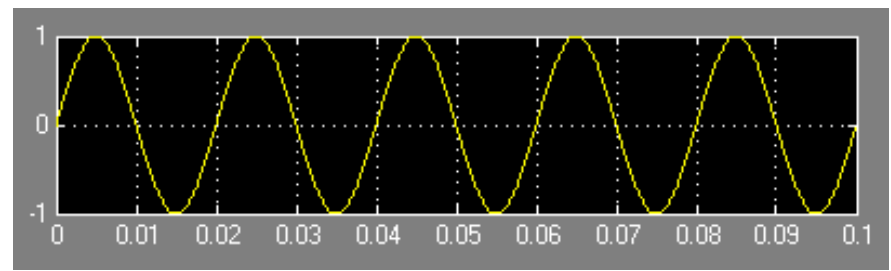

Figure 5: Voltage Input

Fuzzy membership sets are designed for the input to the fuzzy logic controller which is the degree of error voltage and the rate of change of error with time. The fuzzy system used will be a mamdani system [15], and the centroids method for defuzzification is used. The input membership function for harmonic error will have three different membership functions: 
negative, zero and positive. Same membership functions are designed for differentiation of error with respect to time but with changed ranges. The output has three membership functions: small, average \& large. The fuzzy rules are in the form of if-then statements. These statements look at both inputs and determine the desired output

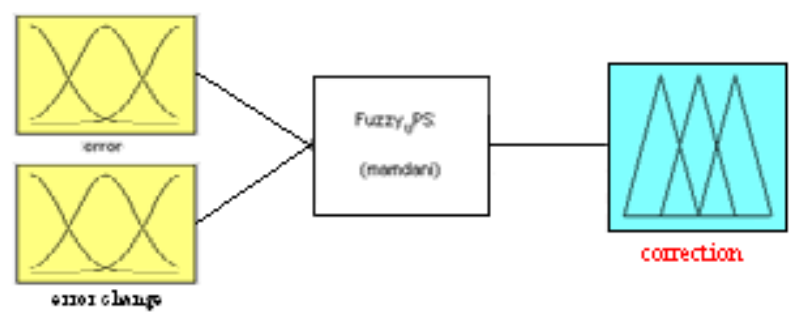

Figure 6: The Fuzzy Logic Controller

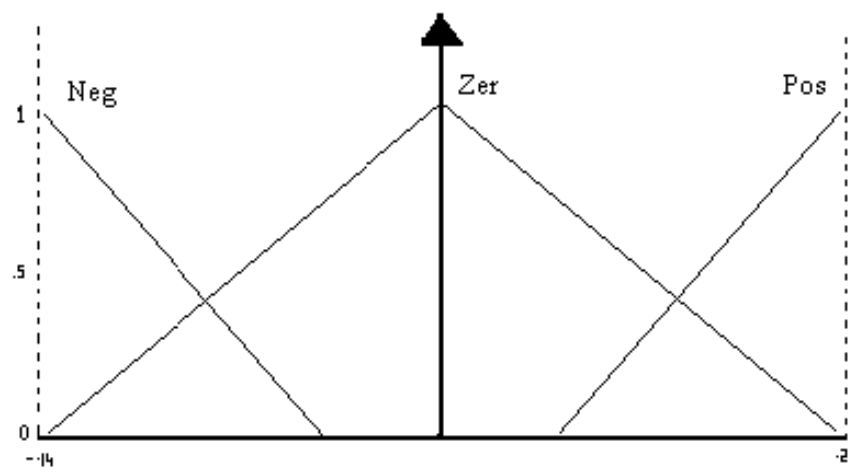

Figure 7: The Error Input Membership Functions

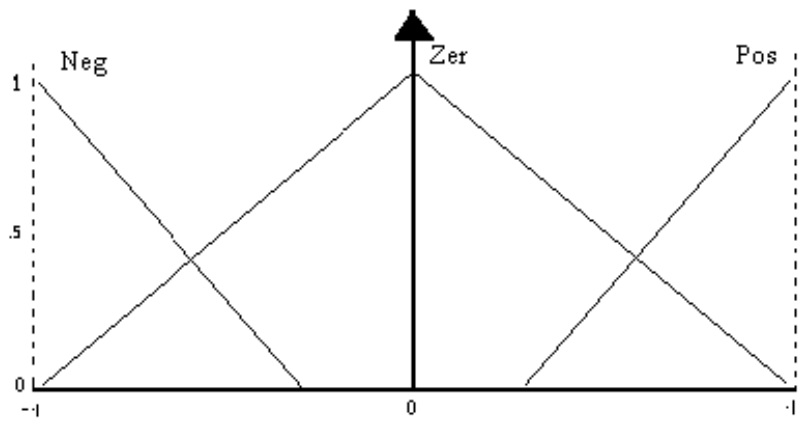

Figure 8: The Error Change Membership Functions

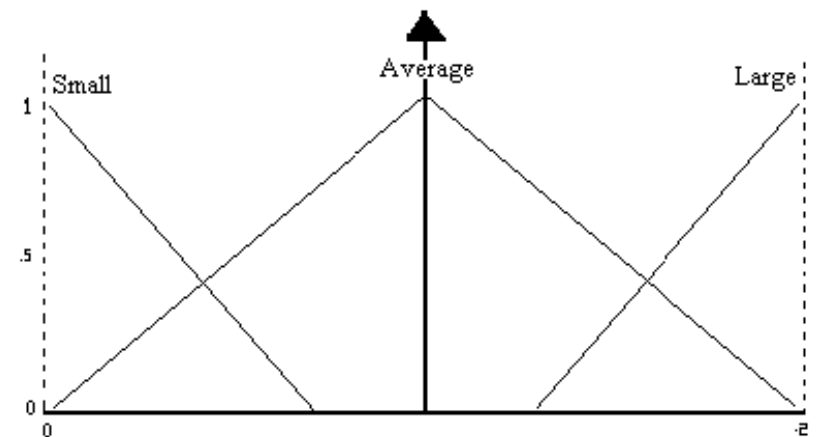

Figure 9: The System Correctness Output Membership Functions
The rules defined for this system are in Table 1 below:

Table 1: Membership Rules

\begin{tabular}{|c|c|c|c|}
\hline ce & $\mathbf{N}$ & $\mathbf{Z}$ & $\mathbf{P}$ \\
\hline $\mathrm{N}$ & $\mathrm{S}$ & $\mathrm{A}$ & $\mathrm{L}$ \\
\hline $\mathrm{Z}$ & $\mathrm{S}$ & $\mathrm{A}$ & $\mathrm{L}$ \\
\hline $\mathrm{P}$ & $\mathrm{S}$ & $\mathrm{A}$ & $\mathrm{L}$ \\
\hline
\end{tabular}

These rules are the defining elements of this system. They determine the output based on the input.

\section{SIMULATION}

The output voltage waveforms of the PWM inverter output using fuzzy logic controller as the main part are presented below in two formats:

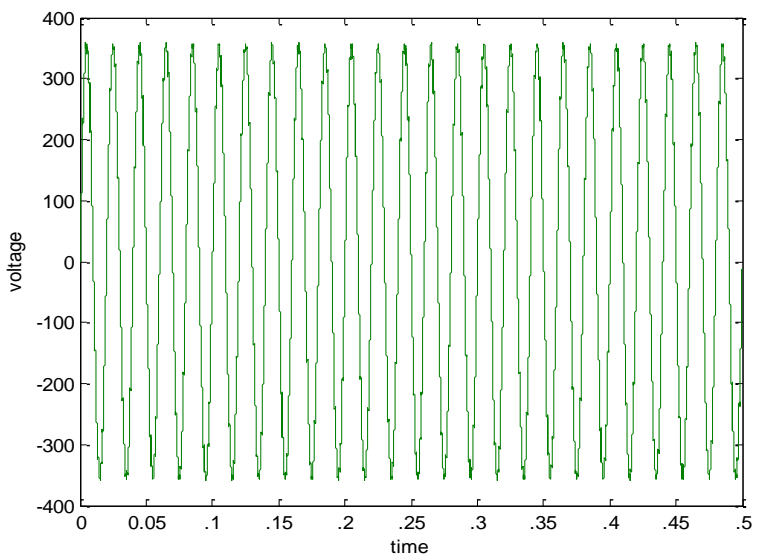

Figure 10: Fuzzy Controller waveform I

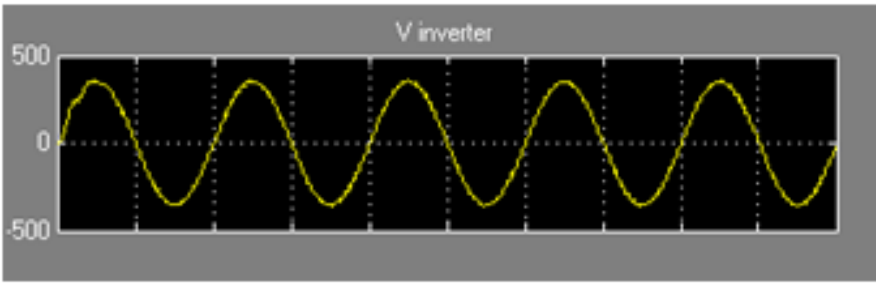

Figure 11: Fuzzy Controller waveform II

As it is quit visible from the wave form that the distortion occurs only in the first cycle of the output waveform due the instability and this factor has been suppressed due to the feedback path provided using fuzzy logic controller.

\section{SIMULATION RESULTS}

In this section, the comparison is made itself with the same system but with different categories of loads which is shown graphically for special cases. Here the PWM inverter output can be taken as both voltage and current depending upon the type of the source of the inverter as: voltage source inverter (VSI) or current source inverter (CSI). The Total Harmonic Distortion (THD) is calculated using FFT analysis tool which is the provided in simulink model in the form of powergui. 
Generally the best and worst cases counted for the Total harmonic Distortion is from $1 \%$ to $13 \%$. But in this system tremendous results have been shown with RL loads along with resistive loads. Firstly, the simulation results are shown for PWM inverter using feedback loop for RL loads and secondly the same procedure is followed with resistive loads in terms of THD for both current and voltage across the load. The results have been shown for 24 cycles.

The results have been demonstrated for both inductive and resistive loads below along with $\mathrm{LC}$ filter. The filter parameters are $\mathrm{L}=0.3 \mathrm{mH} \& \mathrm{C}=1000 \mu \mathrm{F}$

Table 2: THD\% for RL loads

\begin{tabular}{|l|ll|l|}
\hline S.No. & \multicolumn{2}{|l|}{$\begin{array}{l}\text { RL Load, } \mathrm{R} \text { in } \boldsymbol{\Omega} \& \mathbf{L} \text { in } \\
\text { mH }\end{array}$} & $\begin{array}{l}\text { THD \% of } \\
\text { AC Voltage }\end{array}$ \\
\hline 1 & $\mathrm{R}=2, \quad \mathrm{~L}=10$ & 0.53 \\
\hline 2 & $\mathrm{R}=6, \quad \mathrm{~L}=3$ & 0.35 \\
\hline 3 & $\mathrm{R}=10, \quad \mathrm{~L}=0.1$ & 0.36 \\
\hline 4 & $\mathrm{R}=17, \quad \mathrm{~L}=0.6$ & 0.43 \\
\hline 5 & $\mathrm{R}=23, \quad \mathrm{~L}=0.7$ & 0.47 \\
\hline
\end{tabular}

Table 3: THD\% for Resistive loads

\begin{tabular}{|l|l|l|}
\hline S.No. & Resistive Load in $\boldsymbol{\Omega}$ & $\begin{array}{l}\text { THD \% of AC } \\
\text { Voltage }\end{array}$ \\
\hline 1 & $\mathrm{R}=0.34$ & 0.22 \\
\hline 2 & $\mathrm{R}=4$ & 0.35 \\
\hline 3 & $\mathrm{R}=12$ & 0.38 \\
\hline 4 & $\mathrm{R}=43$ & 0.52 \\
\hline 5 & $\mathrm{R}=52$ & 0.54 \\
\hline
\end{tabular}

FFT analysis for minimum achieved THD \% in both the cases is presented below:

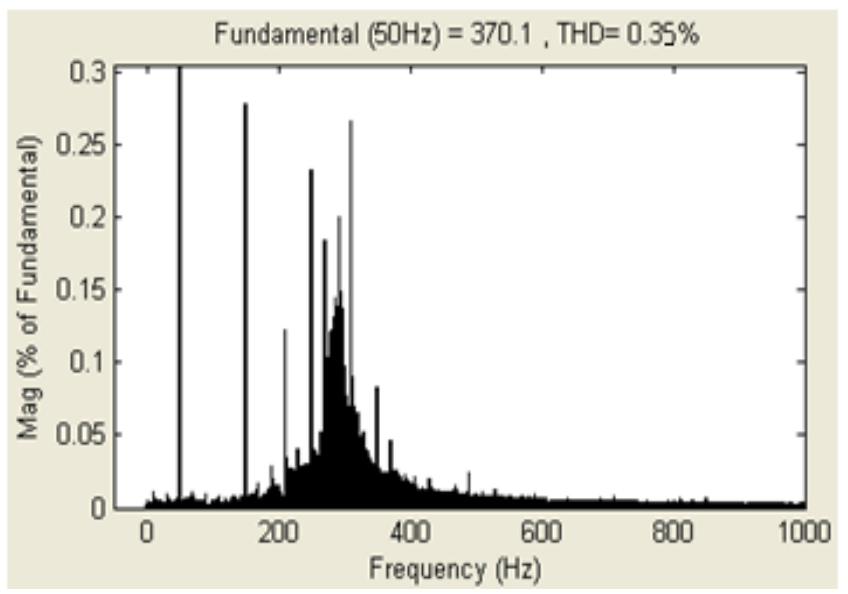

Figure 12: THD\% for RL load

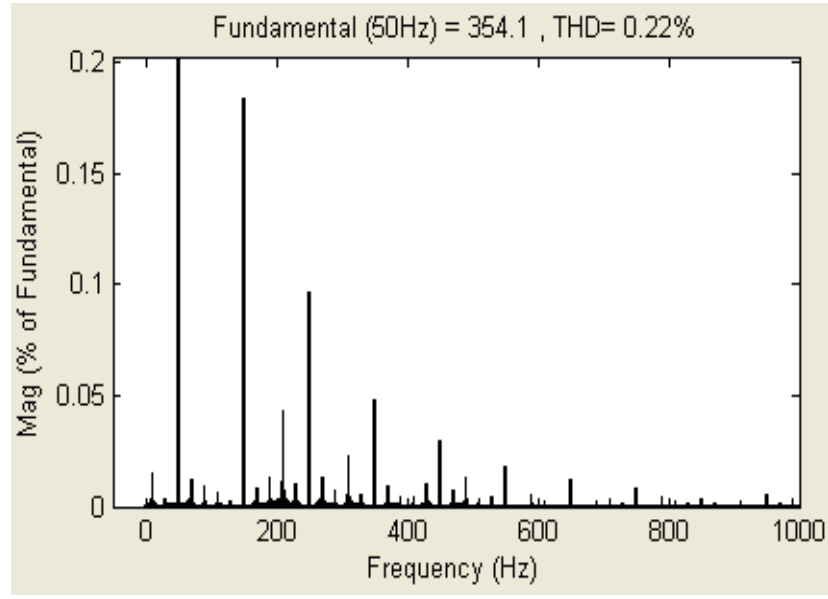

Figure 13: THD\% for Resistive load

These results can be compared and analyzed with the previous technologies which were used for reducing the THD in case of inverters. This comparison has shown the tremendous advancement of the designed FLC model over those technologies which have been developed in recent years. For this a comparative analysis recent years data regarding this is provided below:

Under the topic, "Use of PWM Techniques for Power Quality Improvement (2009)", Out of all PWM technique the modified SPWM technique is best. The THD is about the limit of $3.76 \%$ [2].

In the paper named "Optimized PID Controller for Both Single Phase Inverter (2011)" , four IGBTs were used to implement the inverter, $4.5 \%$ THD was achieved, and tracking for the maximum power using SEPIC was attained, all via optimization for PID controller [16].

\section{CONCLUSION}

A complete simulation model of a single phase pulse width modulated inverter has been proposed using Matlab/Simulink software. The model consists of $\mathrm{H}$ bridge inverter power circuit, filter along with load, firing circuit and fuzzy logic control circuit. A SPWM control technique is adopted in the firing circuit to provide an acceptable control in the inverter output voltage. Tests prove that with this inverter strategy, the low order harmonics are substantially reduced.

This paper has presented the absolute analysis for the total harmonic distortion for single phase PWM inverters with FLCs. The simulated systems indicate the potential for using such a procedure for studying complex systems and performing a meaningful evaluation and/or analysis of the impact of harmonic distortion on a power system for uninterruptable supply. 


\section{REFERENCES}

[1] Oliva A.R. ; Ang S.S. ; Balda J.C. ; Chiacchiarini H.G., "Harmonic distortion reduction in power inverters", Power Electronics Specialists Conference, IEEE 35th Annual, Page(s): 1226 - 1231 Vol.2 , June 2004.

[2] Mahesh A. Patel et al, "Use of PWM Techniques for Power Quality Improvement", IEEE press Series on power engineering, Wiley Interscience Publication, 2003.

[3] D.G. Holmes and T.A. Lippo, "Pulse Width Modulation for Power Converters - Principles and Practice", IEEE press Series on power engineering, Wiley Interscience Publication, 2003.

[4] Wing-Chi So, Chi K. Tse, and Yim-Shu Lee, "Development of a Fuzzy Logic Controller for DC/DC Converters: Design, Computer Simulation, and Experimental Evaluation," IEEE Trans. Power. Electron., vol. 11, NO. 1, pp. 24-32, 1996.

[5] Astrom KJ, Hagglund T (1995). PID Controllers: Theory, Design and Tuning. Instrument Society of America, Research Triangle Park, NC.

[6] L.A. Zadeh, Outline of A New Approach to the Analysis of Complex Systems and Decision Processes, 1973.

[7] Halpin S.M., "Harmonics in Power Systems", in The Electric Power Engineering Handbook, L.L. Grigsby, Ed. Boca Raton: CRC Press, 2001.

[8] Robert J. Scoff, PE "How harmonics are generated" http://www.pdhengineer.com/courses/e/E-3018.pdf
[9] B. J Choi, S.W. Kwak and B. K.Kim, "Design and Stability Analysis of Single-Input Fuzzy Logic Controller", IEEE Trans. Sys., Man \& Cybernetics-Part B Cybernetics, Vol.30, No. 2, pp. 303-309, Apr. 2000

[10] The MathWorks. [online]. Fuzzy Logic Toolbox. Available: http://www.mathworks.com/products/fuzzylogic/

[11] George J. Klir \& Bo Yuan, "Fuzzy Sets and Fuzzy Logic, Theory and Applications", Prentice-Hill India Private Limited, $7^{\mathrm{TH}}$ Edition, 2002.

[12] Raj Kumar Bansal, Ashok Goel, Manoj Kumar Sharma, "MATLAB Applications in Fuzzy Logic Systems", MATLAB and its Applications in Engineering, Page No.391-423, Pearson Education.

[13] Chuen Chien Lee, "Fuzzy Logic in Control Systems: Fuzzy Logic Controller-Part I" , IEEE transactions on Systems, Man and Cybernetics, Vol 20 ,No. 2,March/April 1990.

[14] Juhng-Perng Su, "A generic stable two-input single-output fuzzy control scheme for nonlinear systems", Industrial Electronics and Applications, 2009. ICIEA 2009. 4th IEEE Conference, May 2009.

[15] Muhammad H. Rashid , "Power Electronics" , $3^{\text {rd }}$ Edition, BH Publications.

[16] El Khateb, A. Rahim, N.A. ; Selvaraj, J. ," Optimized PID controller for single phase inverter," Electric Machines \& Drives Conference (IEMDC), 2011 IEEE International, May 2011. 